\title{
Glioblastoma-derived spheroid cultures as an experimental model for analysis of EGFR anomalies
}

\author{
Monika Witusik-Perkowska $\cdot$ Piotr Rieske • Krystyna Hułas-Bigoszewska • \\ Magdalena Zakrzewska • Robert Stawski • Dominika Kulczycka-Wojdala • \\ Michał Bieńkowski • Ewelina Stoczyńska-Fidelus · Sylwia M. Grešner • \\ Sylwester Piaskowski • Dariusz J. Jaskólski • Wielisław Papierz • \\ Krzysztof Zakrzewski $\cdot$ Maciej Kolasa $\cdot$ James W. Ironside $\cdot$ Paweł P. Liberski
}

Received: 30 March 2010/ Accepted: 9 August 2010/Published online: 29 August 2010

(C) The Author(s) 2010. This article is published with open access at Springerlink.com

\begin{abstract}
Glioblastoma cell cultures in vitro are frequently used for investigations on the biology of tumors or new therapeutic approaches. Recent reports have emphasized the importance of cell culture type for maintenance of tumor original features. Nevertheless, the ability of GBM cells to preserve EGFR overdosage in vitro remains controversial. Our experimental approach was based on quantitative analysis of EGFR gene dosage in vitro both at DNA and mRNA level. Real-time PCR data were verified with a FISH method allowing for a distinction between $E G F R$ amplification and polysomy 7. We demonstrated that $E G F R$ amplification accompanied by EGFRwt overexpression was maintained in spheroids, but these phenomena were gradually lost in adherent culture. We noticed a rapid decrease of $E G F R$ overdosage already at the initial stage of cell culture establishment. In contrast to $E G F R$ amplification, the maintenance of polysomy 7 resulted in EGFR locus gain and stabilization even in longterm adherent culture in serum presence. Surprisingly, the
\end{abstract}

M. Witusik-Perkowska ( $₫) \cdot$ P. Rieske $\cdot$ K. Hułas-Bigoszewska ·

M. Zakrzewska · R. Stawski · D. Kulczycka-Wojdala ·

M. Bieńkowski · E. Stoczyńska-Fidelus .

S. M. Grešner · S. Piaskowski · P. P. Liberski

Department of Molecular Pathology and Neuropathology,

Medical University of Lodz, Czechoslowacka 8/10 str,

92-216 Lodz, Poland

e-mail: monika.witusik-perkowska@umed.lodz.pl;

monikawitusik@interia.pl

D. J. Jaskólski

Department of Neurosurgery, Medical University of Lodz,

Kopcinskiego 22 str, 90-153 Lodz, Poland

W. Papierz

Department of Pathomorphology, Medical University of Lodz,

Czechoslowacka 8/10 str, 92-216 Lodz, Poland
EGFRwt expression pattern did not reflect the latter phenomenon and we observed no overexpression of the tested gene. Moreover, quantitative analysis demonstrated that expression of the truncated variant of receptor-EGFRvIII was preserved in GBM-derived spheroids at a level comparable to the initial tumor tissue. Our findings are especially important in the light of research using glioblastoma culture as the experimental model for testing novel EGFRtargeted therapeutics in vitro, with special emphasis on the most common mutated form of receptor-EGFRvIII.

Keywords Glioblastoma - Cell cultures · Spheroids · EGFR amplification · EGFRvIII

\section{Introduction}

One of genetic hallmarks of glioblastoma (GBM) is EGFR (epidermal growth factor receptor) gene amplification,

K. Zakrzewski

Department of Neurosurgery, Polish Mother's Memorial

Hospital Research Institute, Rzgowska 281/289 str,

93-338 Lodz, Poland

M. Kolasa

Department of Neurosurgery, Copernicus Hospital in Lodz,

Pabianicka 62 str, 93-513 Lodz, Poland

J. W. Ironside

National Creutzfeldt-Jakob Disease Surveillance Unit,

University of Edinburgh, Western General Hospital,

Edinburgh EH4 2XU, UK 
occurring in $30-40 \%$ of primary GBM $[1,2]$. This alteration is regarded as an in vivo phenomenon difficult to sustain in vitro in glioblastoma-derived, traditional cell cultures. Therefore, the genetically modified GBM cell lines with artificial EGFR gene aberrations and xenograft technology became alternative models for analyses requiring EGFR overdosage [3-5]. In addition, numerous GBMs present rearrangements and mutations of EGFR gene. EGFRvIII (EGFR. $\Delta 2-7$ ) is the most common mutated variant characterized by a truncation of 267 amino acids within the extracellular domain of the protein, resulting in a constitutive activity of the receptor [6]. Aberrant signaling induced by EGFR gene overdosage or mutations makes epidermal growth factor receptor an interesting target for therapeutic investigations with a special emphasis on EGFRvIII [7, 8].

Glioblastoma cell cultures are frequently used for investigations targeted at the biology of the tumor, or for searching for new therapeutic approaches. However, recent reports have emphasized the importance of cell culture type and conditions for the maintenance of genetic profile of original tumors [9-13]. The comparison of molecular characteristics of GBM cells in vitro revealed differences between spheroids and monolayer cell culture, indicating spheroid cultures as the best tool in which the original genetic profile of the tumor is preserved [11]. This finding seems to be consistent with our previous data suggesting that GBM-derived spherical aggregates are able to maintain certain molecular and phenotypic features of primary cancer cells [14].

The priority of our present investigation was to evaluate the status of EGFR gene, including EGFRvIII, as the most common mutated variant in GBM cells cultured as either spherical aggregates/spheroids or monolayer.

\section{Materials and methods}

Cell culture

\section{Glioblastoma samples}

Tumor samples were obtained from patients with GBM who underwent neurosurgery at the following hospitals: Department of Neurosurgery, Polish Mother's Memorial Hospital, Lodz; Department of Neurosurgery, Medical University of Lodz; Department of Neurosurgery, Copernicus Hospital, Lodz, Poland. All samples were collected under protocols approved by the ethical committee of Medical University of Lodz. The diagnosis was made by histopathology and, when appropriate, immunohistochemistry.
Establishment and growth of adherent glioblastoma cell cultures

The tumor cells were dispersed by means of collagenase type IV $\left(200 \mathrm{u} / \mathrm{ml}, 37^{\circ} \mathrm{C}\right.$ for $\left.6 \mathrm{~h}\right)$. Subsequently, the cells were cultured in $\alpha$ MEM medium containing $10 \%$ FBS (Gibco). Depending on proliferation activity, the cells were passaged to new culture dish every 3-10 days.

\section{Establishment and growth of spheroid glioblastoma cell cultures}

The tumor cells were dispersed by means of collagenase type IV $\left(200 \mathrm{u} / \mathrm{ml}, 37^{\circ} \mathrm{C}\right.$ for $\left.6 \mathrm{~h}\right)$. Subsequently, the cells had been cultured for $12 \mathrm{~h}$ in expansion medium ( $\alpha$ MEM with $10 \%$ FBS), then the medium was changed to the serum-starvation medium. The obtained spherical aggregates were isolated after 1-4 days of incubation and transferred to the cell culture dishes covered with Matrigel (BD Biosciences) and cultured in Neurobasal serum-free medium supplemented with $\mathrm{N} 2$ and B27 $(0.5 \times$ each; Invitrogen) with addition of human recombinant bFGF and EGF $(50 \mathrm{ng} / \mathrm{ml}$ each; Invitrogen). The aggregates were cultured up to 8-12 weeks, and transferred every 5-15 days.

\section{BrdU incorporation assay}

To assess the proliferation of glioblastoma cells in culture, $10 \mu \mathrm{M}$ BrdU (Sigma), a marker of DNA synthesis, was added to the cells cultured as spherical aggregates and subsequent passages of adherent culture. After $48 \mathrm{~h}$ of incorporation, the tested cultures were processed for immunocytochemistry. For BrdU staining, immunocytochemistry was performed according to the manufacturer's protocol with the use of primary antibodies (mouse antiBrdU, 1:500; Sigma) and secondary antibodies (donkey anti-mouse AlexaFluor ${ }^{\circledR}$ 594, 1:250; Molecular Probes). Then, the slides were treated with the ProLong ${ }^{\circledR}$ Gold Antifade Reagent (Molecular Probes), coverslipped and examined, using an Olympus BX-41 fluorescence microscope.

EGFR gene dosage analysis at DNA and mRNA level

\section{DNA and RNA isolation}

For molecular analyses, DNA and RNA were isolated simultaneously with the use of AllPrep DNA/RNA Mini kit (Qiagen) from original tumor samples, subsequent passages of adherent cell cultures and spherical aggregates at the final stage of their culture. 


\section{Quantitative real-time PCR at DNA level}

To determine the EGFR gene dosage level in original tumor tissue, cells cultured as spheroids, and monolayer, quantitative real-time PCR was performed using RotorGene 6000 instrument (Corbett Life Science). The following EGFR primers were used for amplification: F: AACCATGCCCGCATTAGCTC; R: AAAGGAATGC AACTTCCCAA.

Each sample was amplified in triplicate in a reaction volume of $10 \mu \mathrm{l}$ containing $50 \mathrm{ng}$ of DNA, $1 \times$ reaction mix with Syto9 (Invitrogen) and forward and reverse primer, $35 \mathrm{ng}$ each. The cycling conditions were as follows: $3 \mathrm{~min}$ at $95^{\circ} \mathrm{C}$ (polymerase activation) followed by 40 cycles of $20 \mathrm{~s}$ at $95^{\circ} \mathrm{C}$ (denaturation), $30 \mathrm{~s}$ at $60^{\circ} \mathrm{C}$ (annealing) and $1 \mathrm{~min}$ at $72^{\circ} \mathrm{C}$ (extension).

RNase $P$ was used as a reference gene for normalization of the target gene dosage level. To confirm the specificity of the amplification signal, the gene dissociation curve was considered in each case. The normalized relative EGFR gene dosage level of the tested samples versus control sample was calculated utilizing the method described previously by Pfaffl et al. [15], based on each sample's average CT value and each gene's average PCR efficiency. As a control sample, DNA derived from non-tumoral tissue (leukocytes) was used, on the assumption that the gene dosage in normal tissue would be 1 . The values higher than 2 were considered as overdosage of the tested gene.

\section{Quantitative real-time $R T$-PCR}

Reverse transcription was performed using QuantiTect reverse transcription kit (Qiagen) according to the manufacturer's protocol. Real-time PCR was performed using RotorGene 6000 instrument (Corbett Life Science). EGFRwt- and EGFRvIII-specific primers were used for amplification of the tested genes. GUSB was used as a reference gene for normalization of the target gene expression level. The primers data were based on previous reports $[16,17]$. Each sample was amplified in triplicate in a reaction volume of $10 \mu \mathrm{l}$ containing $50 \mathrm{ng}$ of cDNA, $1 \times$ reaction mix with Syto9 and forward and reverse primer, $35 \mathrm{ng}$ each. The cycling conditions were as follows: $3 \mathrm{~min}$ at $95^{\circ} \mathrm{C}$ (polymerase activation) followed by 40 cycles of $20 \mathrm{~s}$ at $95^{\circ} \mathrm{C}$ (denaturation), $30 \mathrm{~s}$ at $60^{\circ} \mathrm{C}$ (annealing) and $1 \mathrm{~min}$ at $72^{\circ} \mathrm{C}$ (extension). To confirm the specificity of the amplification signal, the gene dissociation curve was considered in each case. Normalized relative expression level of EGFRwt or EGFRvIII gene in the tested samples versus control sample was calculated utilizing the method described previously by Pfaffl et al. [15], based on each sample's average CT value and each gene's average PCR efficiency. In the case of EGFRwt expression analysis, the cDNA derived from normal human astrocytes (NHA, Lonza, formerly Cambrex) was used as a control sample. To evaluate EGFRvIII expression, cDNA derived from tumor tissue positive for EGFRvIII was used as a control.

The real-time PCR was preceded by conventional RTPCR applied to examine the tested tumor samples in terms of EGFRvIII expression. The results were obtained with the use of two pairs of primers described previously [16], and visualized on agarose gel.

\section{Fluorescence in situ hybridization (FISH)}

A commercial probe set (LSI EGFR SpectrumOrange/CEP 7 SpectrumGreen, no 32-191053; Vysis) was used for simultaneous determination of the EGFR gene and chromosome 7 copy numbers. FISH was performed in the following way: the fixed slides were incubated in $2 \times$ standard saline citrate (SSC) at $72^{\circ} \mathrm{C}$ for $5 \mathrm{~min}$. The slides were then placed in 70 , 85 and $100 \%$ ethanol for 1 min each, air-dried and placed on a $50^{\circ} \mathrm{C}$ slide warmer for $2 \mathrm{~min}$. The FISH probe set mix $(1 \mu \mathrm{l}$ LSI DNA probe mix, $7 \mu \mathrm{l}$ LSI Hybridization Buffer and $2 \mu \mathrm{l}$ water) was centrifuged and denatured at $73^{\circ} \mathrm{C}$ for $5 \mathrm{~min}$. The denatured probe was placed in each specimen. The slides were then coverslipped and incubated at $37^{\circ} \mathrm{C}$ overnight in a humidified chamber. Afterwards, the slides were washed with $0.4 \mathrm{x} \mathrm{SSC} / 0.3 \% \mathrm{NP}-40$ at $73^{\circ} \mathrm{C}$ for $15 \mathrm{~min}$ and rinsed in $2 \times \mathrm{SSC} / 0.1 \% \mathrm{NP}-40.10 \mu \mathrm{l}$ of DAPI II counterstain were placed on the slides and coverslipped. For the scoring, an Olympus BX-41 fluorescence microscope was used, equipped with a specially designed filter combination for green and orange spectra.

The number of red signals, corresponding to the EGFRspecific probe, is directly related to the number of copies of EGFR. The number of green signals, corresponding to the centromeric region of chromosome 7 , is directly related to the number of copies of chromosome 7 .

FISH evaluation was performed according to previously published criteria [1]. The EGFR/CEP 7 ratio was calculated. Ratios of 2 and greater were considered amplified. Ratios less than 2 were considered nonamplified. Polysomy 7 was defined as the nuclei contained three or more signals specific for CEP 7.

Immunocytochemistry

For immunocytochemical analysis, cell cultures were fixed for $15 \mathrm{~min}$ in $4 \%$ paraformaldehyde in PBS (and permeabilized with $0.1 \%$ Triton $\mathrm{X}-100$ for $10 \mathrm{~min}$ for SOX2 detection). Nonspecific binding sites were blocked with $2 \%$ donkey serum in PBS for $1 \mathrm{~h}$. Subsequently, the cells were incubated for $1 \mathrm{~h}$ with the following antibodies: rabbit polyclonal antibody against SOX2 (1:1,000, Chemicon) or mouse monoclonal antibody against EGFR (528) (1:100; 
Santa Cruz Biotechnology). For visualization, the appropriate species-specific fluorochrome-conjugated secondary antibodies (1:250, donkey anti-rabbit AlexaFluor ${ }^{\circledR} 488$, 1:250, donkey anti-mouse Alexa-Fluor ${ }^{\circledR} 594$; Molecular Probes) were applied for $1 \mathrm{~h}$ in dark. Controls with secondary antibodies alone, and with matched isotype controls in place of primary antibodies were processed in the same manner. Slides were mounted with ProLong ${ }^{\circledR}$ Gold Antifade Reagent with DAPI (Molecular Probes), coverslipped and examined using an Olympus BX-41 fluorescence microscope.

Invasion assay

The invasion assay was performed with the use of Matrigel invasion chambers (BD Biosciences) according to manufacturer's protocol. To investigate the invasion potential of GBM-derived spheroids versus adherent cells, the cultures were established from tumor tissue originally showing EGFR overdosage (amplification). The spheroids and adherent cells were cultured according to protocols presented above up to 3-4 weeks (passage 5 of adherent culture). Then, the cells were plated in the top well of prehydrated Matrigel invasion chambers at a density of $2 \times$ $10^{4}$ cells/well or respectively 10 spheroids/well in DMEM supplemented with $0.1 \%$ FBS (the number of cells in spheroids was assessed according to criteria published previously [18]). The bottom wells were provided with DMEM supplemented with $10 \%$ FBS. Cells were allowed to invade for $40 \mathrm{~h}$. Afterwards, the cells from the top of the chambers were removed and the filters were fixed in $4 \%$ paraformaldehyde (Sigma) in PBS for 15 min and subsequently stained fluorescently with DAPI. Invasion was quantified by counting of the cell number on the underside of the filter from 3 fields using an Olympus BX-41 fluorescence microscope. The data were expressed as the average number (means \pm $\mathrm{SD}$ ) of cells from 3 fields that invaded to the lower surface of the filter from each of 4 experiments performed.

Alternative approach to verify invasion ability of spheroids was applied according to simplified method described previously [19].

The GBM-derived spheroids were implanted and cultured into three-dimensional Matrigel. The invasion process was monitored using an inverted microscope (Olympus) and visualized as photomicrographs.

\section{Statistical analysis}

The real-time PCR data were expressed as the means \pm SD. The invasion results were expressed as the average number (means $\pm \mathrm{SD}$ ) of cells from 3 fields that invaded to the lower surface of the filter from each of 4 experiments performed. The data were analyzed by nonparametric methods. When more than two groups were analyzed, the
Kruskal-Wallis test was used, initially to identify a difference and, if this proved significant, individual groups were further investigated using Conover-Inman, a nonparametric posthoc test. In order to compare two groups, the Mann-Whitney $U$ test was used. In all tests, $P<0.05$ was considered significant.

\section{Results}

Establishment and basic characteristics of glioblastoma cell cultures derived from the tumors presenting increased $E G F R$ gene dosage

Initially, the 13 samples of GBM were examined for $E G F R$ gene dosage using real-time PCR. Those GBM samples with clear $E G F R$ overdosage (values describing relative $E G F R$ dosage above 2) were further used for cell cultures establishment (G1, G16, G32, G33, G48, G54; Fig. 1).

Cells derived from the selected tumors were cultured as monolayer and spherical aggregates/spheroids (Fig. 2) either in the presence of serum or in serum-free conditions, depending on their inherent tendency to adherent or a spherical growth. The serum-free medium was the factor most favorable to spherical aggregates, which could be propagated in these conditions up to 3 months reaching the size of $200-500 \mu \mathrm{m}$ depending on particular examined tumors. The attempts to propagate spherical aggregates in a presence of serum led to dispersal of the cells in a short time.

The G1-, G32-, G48-, and G54-derived cells were grown as a short-term adherent cultures until passage 10th at most (8-12 weeks), by which time they became senescent. The long-term cultures were obtained from G16 and G33 tumors (20-24 weeks). The cultures were terminated at the passage 25 for G33 and the passage 50 for G16, although

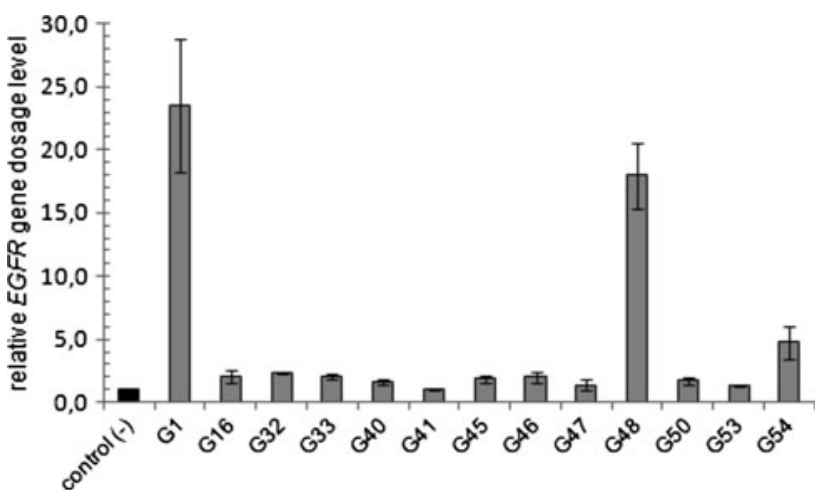

Fig. 1 Initial evaluation of EGFR gene dosage in glioblastoma tumors. Results of real-time PCR (means \pm SD) allowed the identification of GBMs exhibiting EGFR overdosage (values describing relative $E G F R$ dosage above 2) 
Fig. 2 Spheroid and adherent cultures of GBM-derived cells. Light photomicrographs presenting the cells derived from the selected tumors with EGFR overdosage cultured as spherical aggregates and monolayer
Fig. 3 Proliferation ability of GBM-derived culture in vitro assessed with BrdU. a The spherical aggregates obtained from tumors showing $E G F R$ amplification demonstrated maintained proliferation ability during the whole period of culture (up to 8-12 weeks). b The short-term adherent cultures derived from GBMs with $E G F R$ amplification showed gradual decrease of proliferative activity to a very low level at the final stage of culture (8-12 weeks). c The proliferation ability was sustained even in long-term adherent cultures derived from tumors showing polysomy 7 (up to 20-24 weeks)
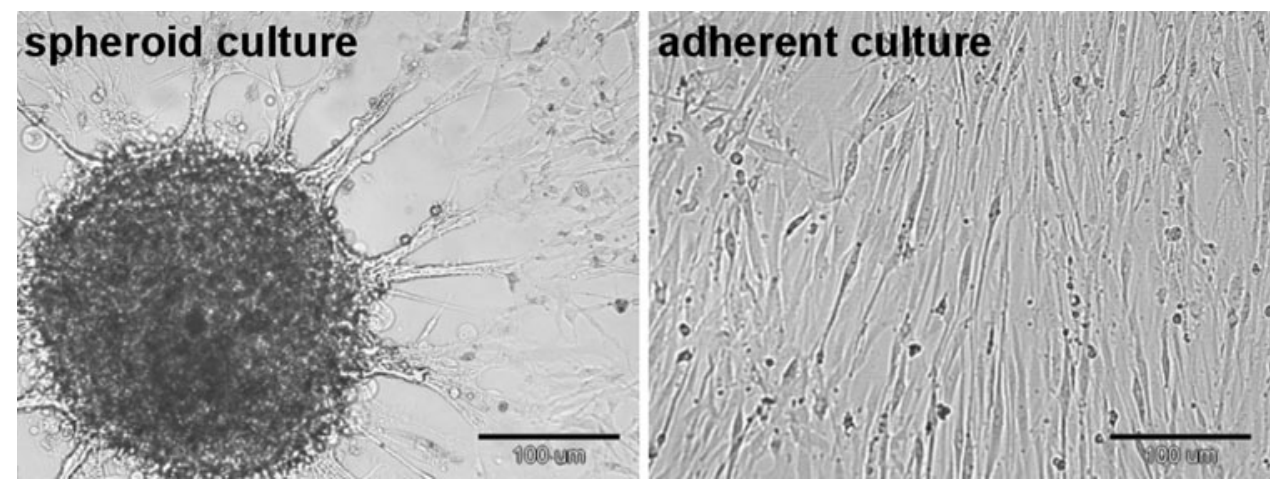

a

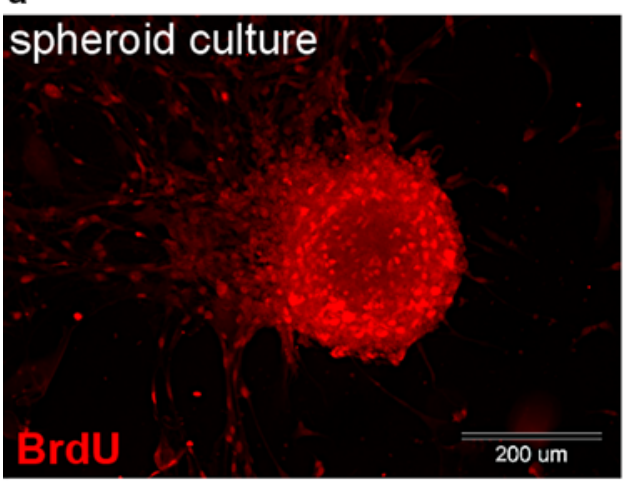

b
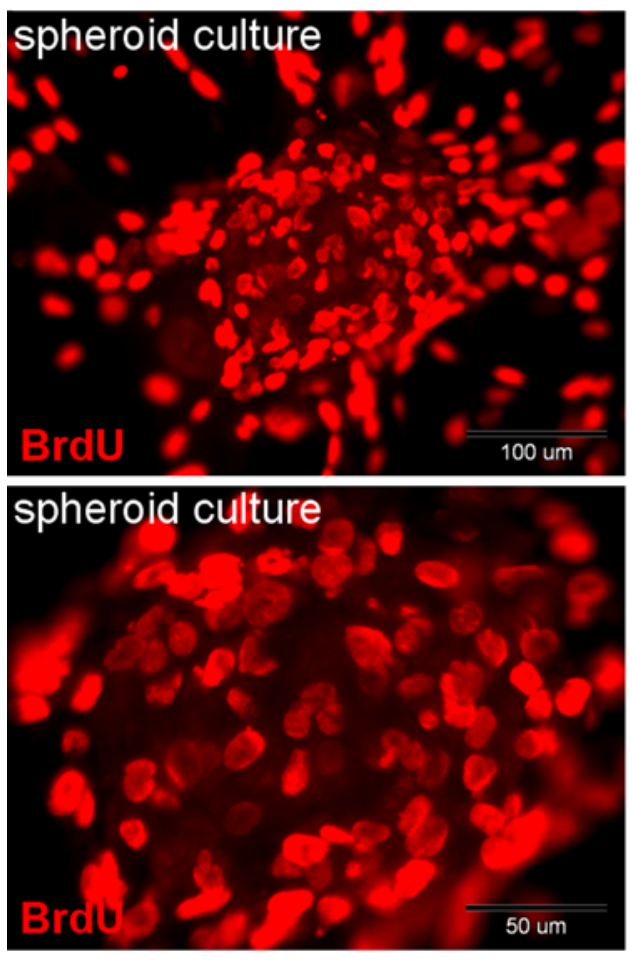
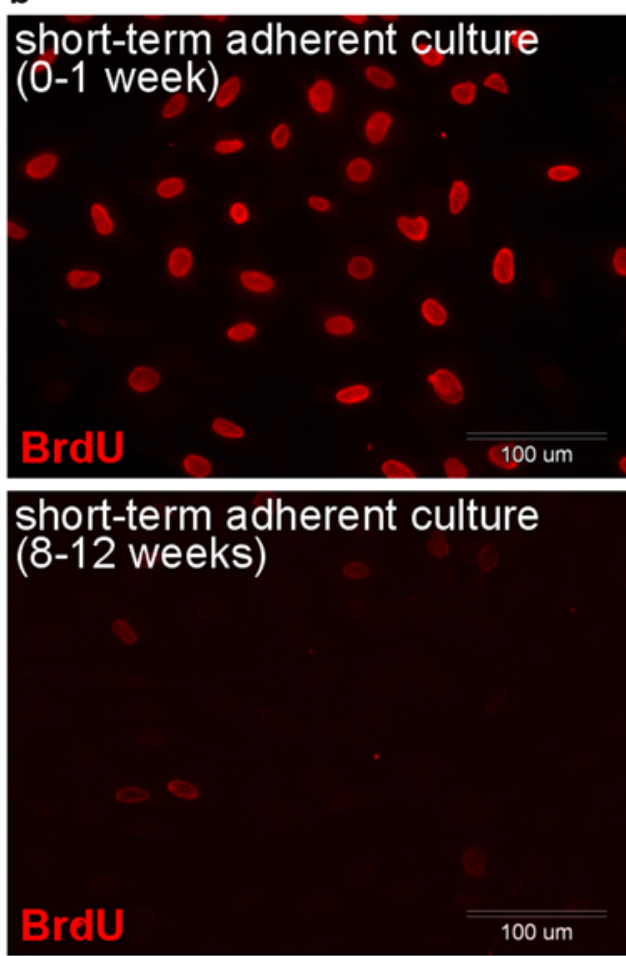

c

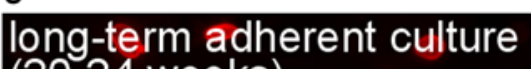
(20-24 weeks)

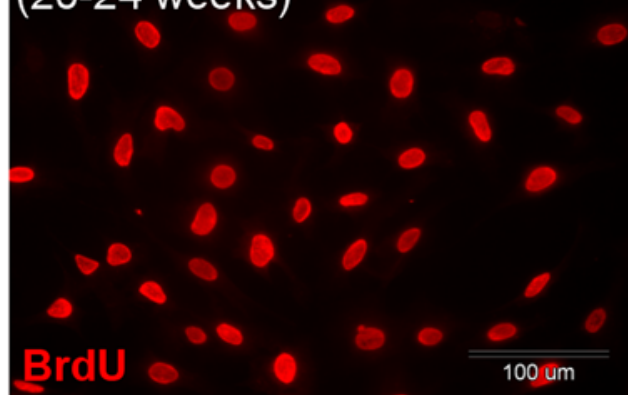

those cells presented no features of senescence. BrdU incorporation assay confirmed that proliferation was maintained within the spherical aggregates during the whole period of culture, in contrast to short-term adherent culture derived from the majority of tested tumors (G1,
G32, G48, G54), except for G16- and G33-derived cells, which showed proliferative activity even in long-term monolayer cultures (Fig. 3).

Additionally, the proliferative and differentiation potential of GBM cells in vitro was examined with the use 
Fig. 4 Proliferative and differentiation potential of GBM cells in vitro evaluated with SOX2 expression. Immunocytochemistry data demonstrated a ability of spheroids to maintain $S O X 2$ expression, and $\mathbf{b}$ gradual loss of this neural stem cell marker in adherent culture a
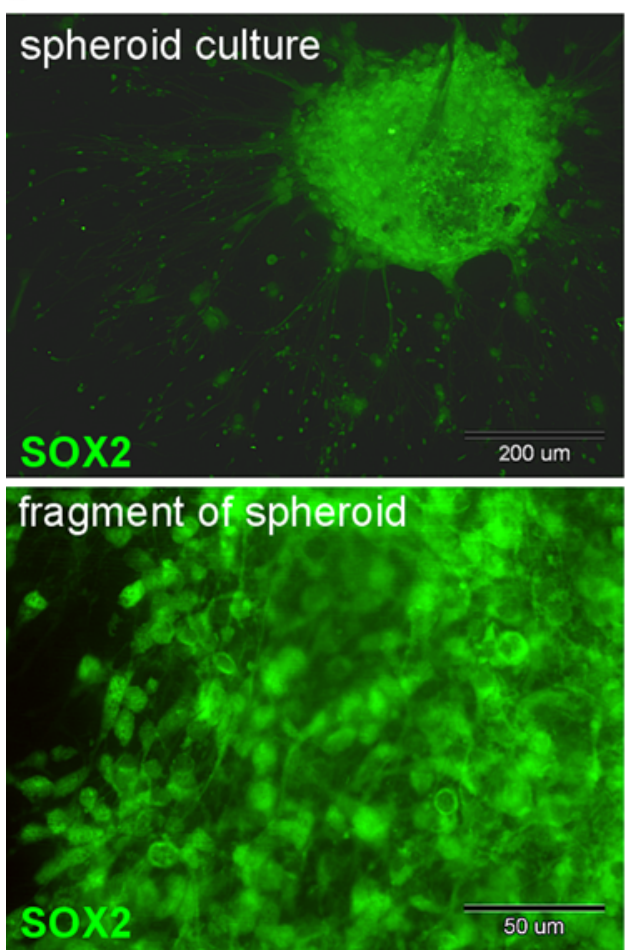

b

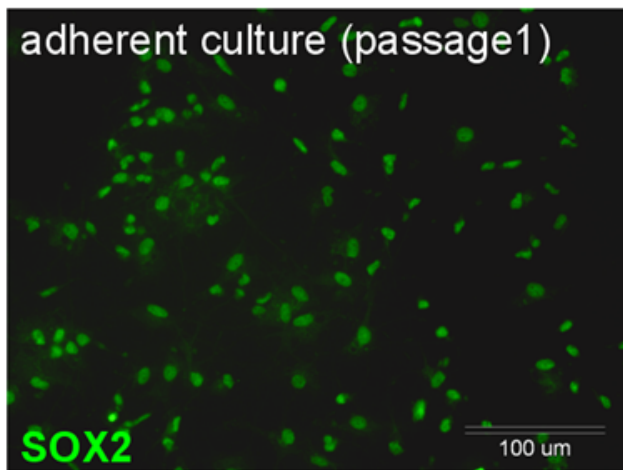

adherent culture (passage 10) of SOX2 status analysis in spheroids and monolayer. The immunocytochemistry assay demonstrated gradual silencing of SOX2 expression in subsequent passages of adherent cells in contrast to spheroids showing ability to maintain high level of SOX2 protein (Fig. 4).

The basic characteristics of tumors selected for further analysis are presented in Table 1. Spherical aggregates and successive passages of adherent cells were used for further investigations, including analyses of EGFR gene dosage status at DNA and mRNA level.

Comparative quantification of EGFR status in GBM cells in vitro was performed for the following cell populations at different stages of culture: G1, G32, G48-passage 0 (0-1 week), passage 5 (3-4 weeks), passage 10 (8-12 weeks), spheroids (8-12 weeks); G16, G33-low passages described as short-term culture (0-12 weeks) versus high passages described as long-term culture (16-24 weeks).
EGFR gene dosage status in adherent and spheroid cultures of glioblastoma cells

The samples with clearly visible EGFR overdosage (G1, G16, G32, G33, G48) were verified by FISH technique that revealed amplification of the tested gene in three cases (G1, G32, G48) and polysomy of chromosome 7 and EGFR locus in two cases (G16, G33) (Fig. 5). In the cases of G1, G32 and G48 samples, the single cells with low polysomy 7 were also observed; nevertheless, their presence did not influence further quantitative analyses. EGFR amplification was a dominant feature in these samples, thus they were classified as EGFR-amplified GBMs. Subsequently, real-time PCR technique was applied to monitor the status of EGFR gene dosage in selected GBM-derived cultures. Quantitative analysis revealed two patterns of $E G F R$ gene dosage changes in the consecutive passages of

Table 1 Characteristics of GBM-derived cultures presenting EGFR overdosage

\begin{tabular}{lllll}
\hline GBM & Adherent culture length ${ }^{\mathrm{a}}$ & Spherical aggregates & EGFR status & EGFRvIII \\
\hline G1 & Short-term (p0-p10) & Yes & Amplification & No \\
G16 & Long-term (p0-p50) & No & Polysomy 7 and EGFR locus & No \\
G32 & Short-term (p0-p5) & Yes & Amplification & No \\
G33 & Long-term (p0-p25) & No & Polysomy 7 and EGFR locus & No \\
G48 & Short-term (p0-p10) & Yes & Amplification & Yes \\
G54 & Passage 0 only & No & Non verified & No
\end{tabular}

${ }^{a}$ Short-term culture (up to 8-12 weeks at most); long-term culture (up to 20-24 weeks at most) 
Fig. 5 Verification of EGFR gene dosage status with the use of FISH method. FISH with an EGFR probe (red signals) and 7q control probe (green signals) confirmed EGFR overdosage in selected GBMs and allowed a distinction between amplification of the tested gene and polysomy 7. G1, G32, and $G 48$ were recognized as samples showing $E G F R$ amplification (accompanied by low polysomy 7 in single cells). G16 and G33 were assessed as GBMs with polysomy 7. EGFR amplification was observed as homogenous or clustered distribution of EGFR signals in cells with EGFR/CEP7 ratio > 2 (representative cells in circles). Polysomy 7 was detected as the nuclei contained three or more signals specific for CEP 7 (representative cells in rectangles). EGFR gene amplification and polysomy 7 was scored as negative if only 2 red signals (EGFR)/2 control green signals (CEP7) were observed

adherent cultures. The short-term monolayer cultures, derived from the tumors with EGFR amplification (G1, G32, G48), showed a gradual decrease of EGFR gene dosage (Fig. 6a). In contrast, two long-term cultures derived from GBMs with polysomy 7 (G16, G33) showed a gain of EGFR dosage at higher passages (Fig. 6b). The analysis of consecutive passages of G16 and G33 suggested a stabilization of EGFR dosage level at the final stage of the culture (data not shown).

Further analysis of EGFR amplification status in GBM cells in vitro revealed no significant changes of gene dosage in the initial cell culture and subsequently derived spherical aggregates in a case of G1 and G32. G48-derived spheroids, compared to the passage 0 , showed a modest decrease of EGFR dosage; nevertheless, they were still able to maintain EGFR amplification at a level higher than the adherent cells (Fig. 6a). However, the comparison of $E G F R$ amplification status in original tumors and cell cultures revealed a rapid decrease of $E G F R$ amplification level already at the initial stage of the culture (p0), eliciting that the EGFR dosage in spheroids was similar to that in cells at passage 0 , but significantly lower when compared to the original tumor tissue (Fig. 6c).

\section{Expression pattern of EGFRwt and EGFRvIII at mRNA}

level in GBM-derived cultures in vitro

Quantitative real-time PCR analysis revealed overexpression of EGFRwt in samples showing EGFR amplification (G1, G48), followed by a gradual downregulation of the tested gene in adherent cultures in the serum presence and maintenance of high level of EGFRwt mRNA in spheroids (Fig. 7a). The cell cultures derived from those tumors showing polysomy 7 (G16, G33) presented distinct patterns of EGFRwt expression. However, in both cases, EGFRwt overexpression was not observed. The G16derived cells showing polysomy 7 expressed EGFRwt at a level similar to the control (NHA) in long-term cultures, while the lower passages demonstrated a decreased expression of the tested gene. The G33-derived cells
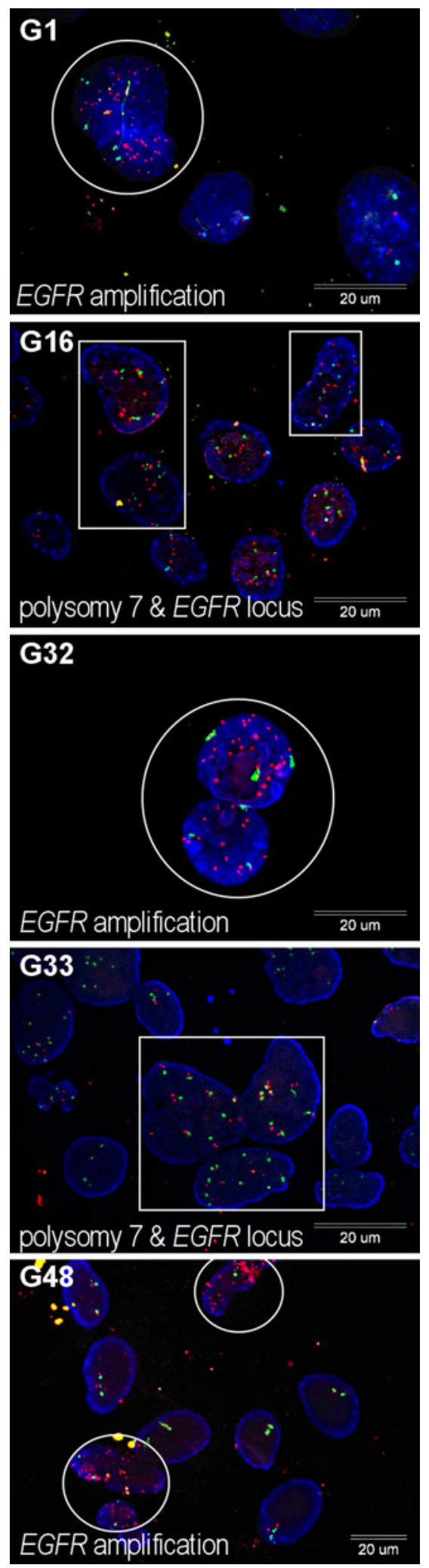

showed underexpression of EGFRwt irrespective of culture length (Fig. 7b).

Additionally, the selected tumors showing EGFR overdosage were evaluated in terms of EGFRvIII presence. On 
Fig. 6 Quantitative analysis of $E G F R$ gene dosage at DNA level. a The short-term monolayer cultures derived from the tumors presenting EGFR amplification $(G 1, G 32, G 48)$ showed gradual decrease of EGFR gene dosage, in contrast to spherical aggregates able to maintain EGFR amplification at a level higher than the adherent cells. b The long-term cultures derived from GBMs with polysomy $7(G 16, G 33)$ showed a gain in EGFR dosage at higher passages. c The initial culture demonstrated a rapid decrease of EGFR amplification level in comparison to the original tumor tissue. Real-time PCR data were presented as means $\pm \mathrm{SD}$; $P<0.05$ was considered significant

the basis of RT-PCR results, only one sample (G48) was classified as EGFRvIII-positive (Fig. 8a). Quantitative analysis of EGFRvIII expression pattern demonstrated a rapid decrease of mRNA level in adherent cells and lack of significant changes in spherical aggregates in comparison to the tumor tissue. However, in contrast to EGFRwt, EGFRvIII level was similar in the tumor tissue and the initial cell culture (Fig. 8b).

Invasive capability of GBM cells cultured as spheroids and monolayer

The GBM-derived cells presenting EGFR overdosage (amplification) in original tumor tissue were used to establish the spheroid and adherent cell cultures. The cells in spheroids and monolayer were cultured up to 3-4 weeks. To assay the invasion capability of cells cultured as spheroids versus adherent cells in vitro the Matrigel-coated invasion chambers were applied (BD Biosciences). The quantitative analysis showed significant difference between the cells number invaded through the Matrigel from spheroids $(55.25 \pm 15.18)$ in comparison to the cells number invaded from monolayer (11.42 \pm 1.07$) ; P=0.03$ (Fig. 9a). The higher invasiveness of the cells cultured in spheroids versus adherent cells was visualized as fluorescent microphotographs of the lower surface of the filters (Fig. 9b). The immunocytochemistry data demonstrated that decrease of invasiveness observed in monolayer was parallel to downregulation of EGFR protein level detected in adherent cells (passage 5, 3-4 weeks of culture) in comparison to spheroids (3-4 weeks of propagation) (Fig. 9c).

In order to confirm the invasiveness of spheroids, an alternative experimental approach was applied based on the three-dimensional invasion assay performed previously by Stein et al. [19]. We showed that the GBM-derived spheroids implanted into Matrigel were able to release the cells from the core. As a result, we observed the cells invading radially into Matrigel and creating the extending invasive rim around the spheroid core (Fig. 9d).

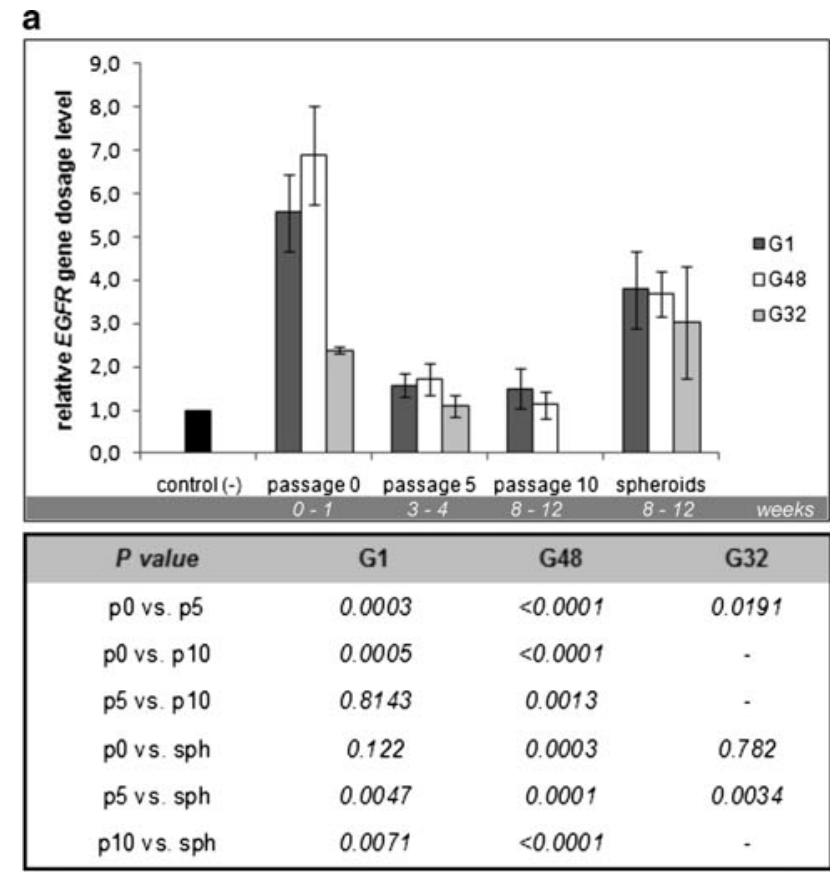

b

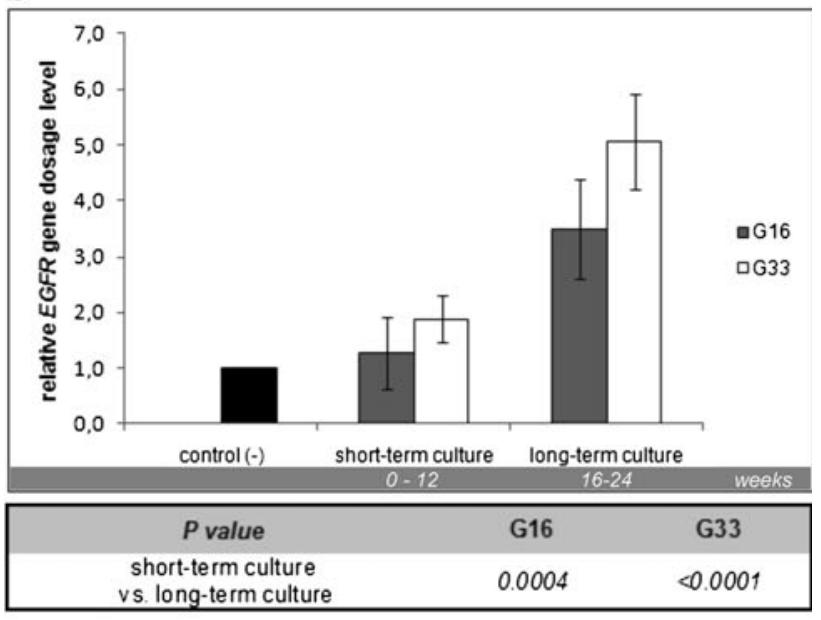

c

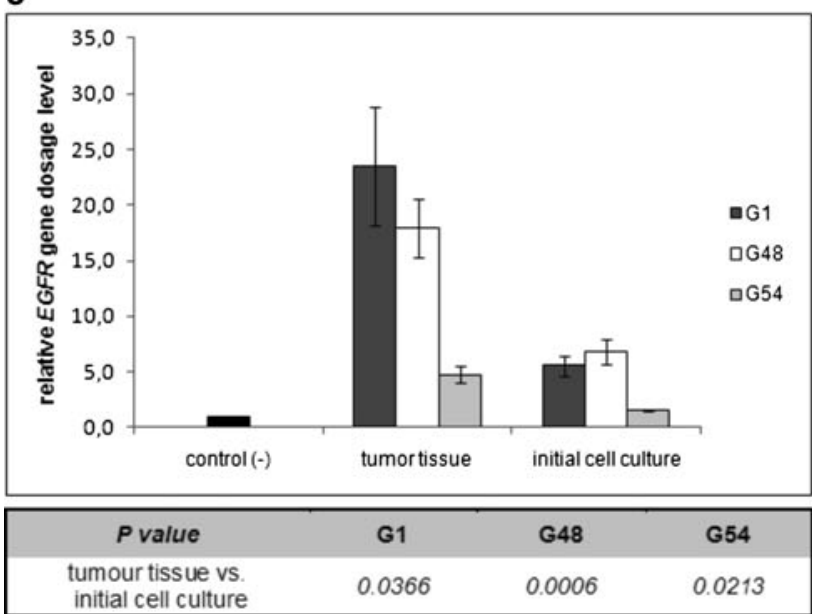




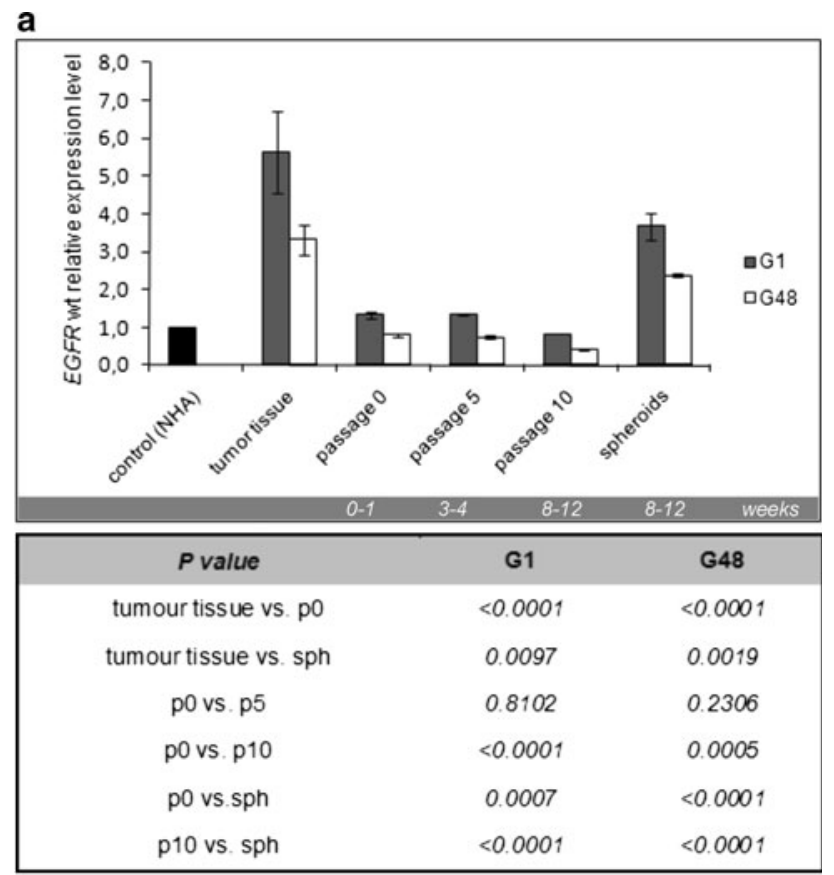

b

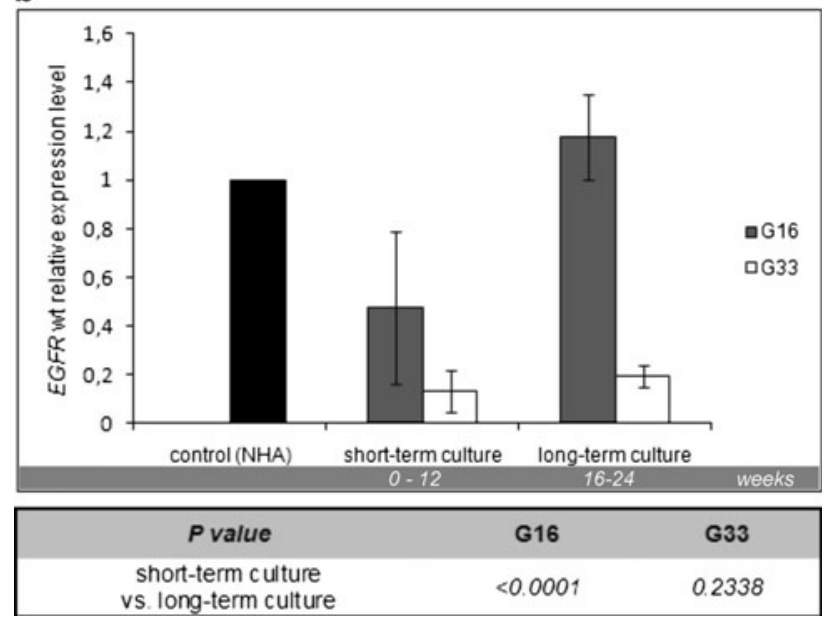

Fig. 7 Quantitative analysis of EGFRwt expression at mRNA level. a The tumors with EGFR amplification $(G 1, G 48)$ showed EGFRwt overexpression, followed by downregulation of the tested gene in adherent culture and maintenance of high level of EGFR mRNA in spheroids. b The cell cultures derived from tumors showing polysomy 7 showed EGFRwt expression at a level similar to control (NHA) in long-term culture (G16), or underexpression of EGFRwt irrespective of the culture length (G33). Real-time PCR data were presented as means $\pm \mathrm{SD} ; P<0.05$ was considered significant

\section{Discussion}

According to Günther et al. [20], GBM-derived cell cultures exhibit an inherent ability either to form spherical aggregates/spheroids or a tendency to adherent growth. Our results, consistent with this scenario, form the basis for a

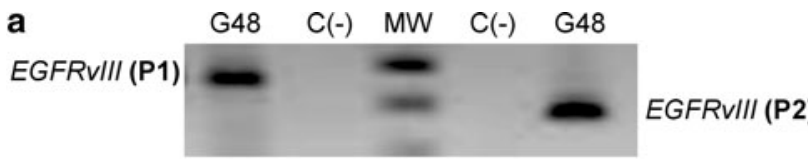

b

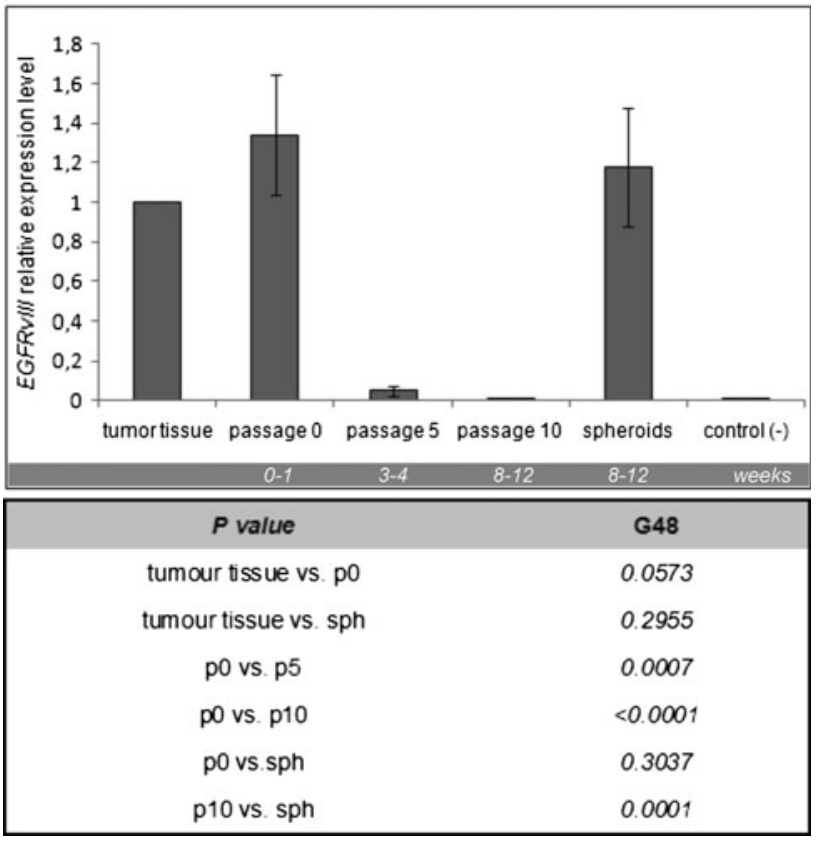

Fig. 8 EGFRvIII expression pattern in G48-derived cell culture. a RT-PCR results carried out with two pair of primers ( $P 1$ amplicon size: $131 \mathrm{bp}$; $P 2$ amplicon size: $90 \mathrm{bp}$ ), singled out $G 48$ as $E G$ FRvIII-positive sample; $C(-)$ negative control; $M W$ molecular weight marker. b Quantitative analysis demonstrated a rapid decrease of EGFRvIII mRNA level in adherent culture at passages 5 and 10, in contrast to spherical aggregates showing EGFRvIII expression at a level similar to the tumor tissue and passage 0. Real-time PCR data were presented as means $\pm \mathrm{SD} ; P<0.05$ was considered significant

comparative analysis of a certain molecular and phenotypic features of spheroid and adherent cultures of GBM cells.

Our initial data based on BrdU assay revealed differences in a proliferation ability of GBM cells cultured as spherical aggregates and monolayer, indicating spheroids as the method of a choice for maintenance of the culture. In contrast, the majority of GBM-derived cultures presented progressive features of senescence under the routine growth conditions. The different proliferative potential of GBM spheroids and adherent cultures examined was additionally emphasized by discrepant expression of SOX 2 recognized as a factor necessary for the continuous proliferation of human glioma cells [21]. Moreover, regarding SOX2 as a neural stem cell marker, we can suppose that spheroids and adherent cells have distinct differentiation status. This suggestion seems to confirm our previous findings demonstrating multilineage phenotype and differentiation potential of GBM cells cultured as spheroids [14]. 
Fig. 9 Invasion ability of GBM spheroids and adherent cells in vitro. a, b The results of comparative invasion assay for spheroid and monolayer cultures established from the tumor tissue originally showing $E G F R$ amplification with the use of Matrigel invasion chambers. a Quantitative data demonstrated decreased invasiveness of GBM cells in monolayer in comparison to spheroids $(P=0.03)$. b The cells invaded through the Matrigel-coated filters were fluorescently stained with DAPI. c The immunocytochemistry data demonstrated downregulation of EGFR protein level in adherent cells in comparison to spheroids, a phenomenon parallel to the decrease of invasiveness. d Visualization of three-dimensional invasion assay for spheroids.

Photomicrogarphs of spheroids implanted into Matrigel at day 1 and day 4 of the culture presented the cells invaded radially from the spheroid core a

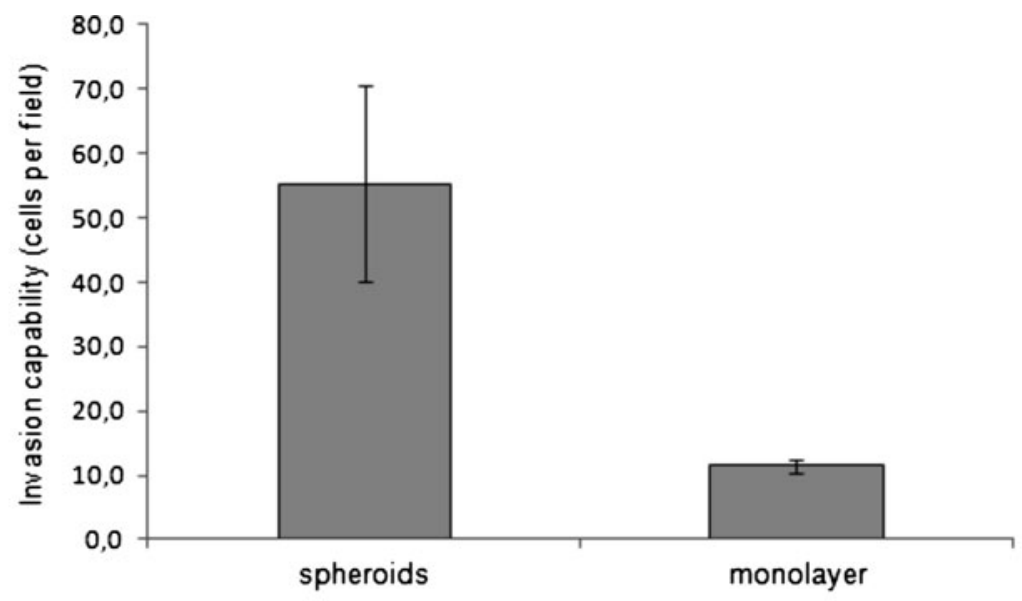

b

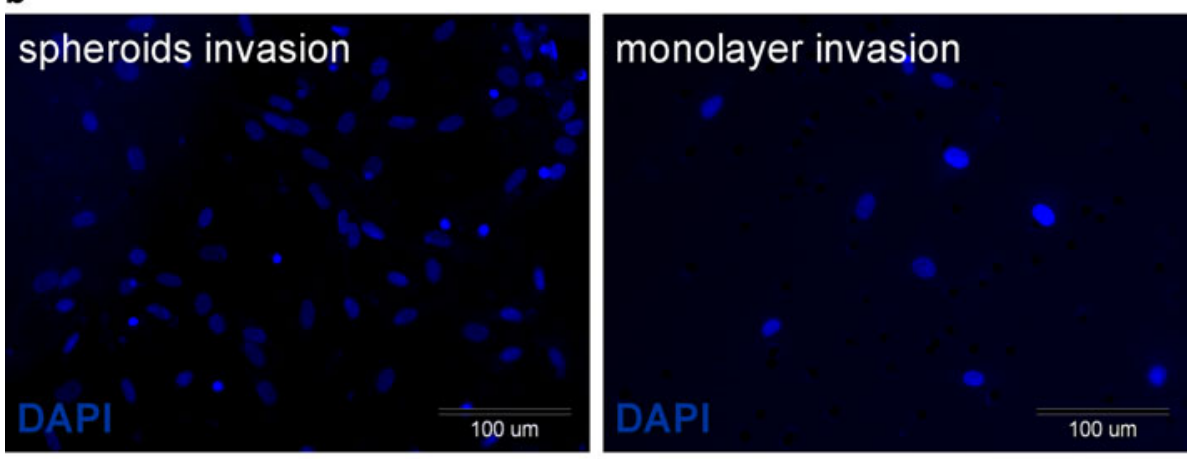

c

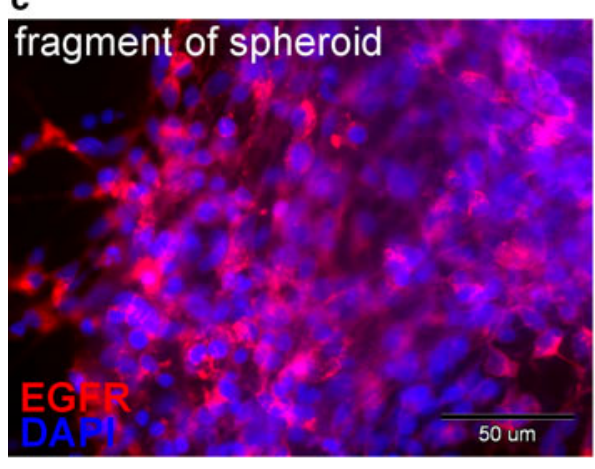

adherent culture (passage 5)
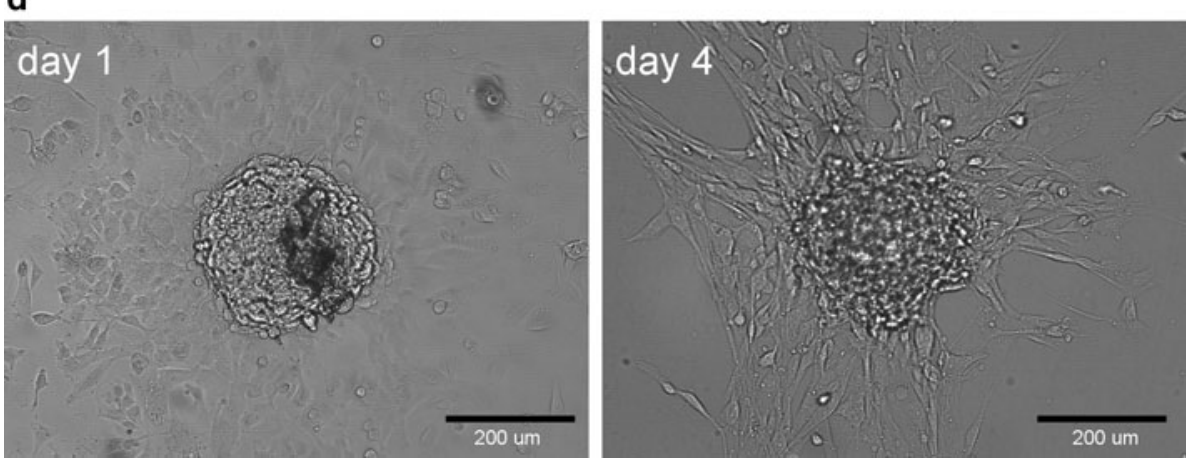
These observations are consistent with several recent reports emphasizing the influence of cell culture type and conditions for the maintenance of the primary features of original tumors [9-13].

Furthermore, we focused on a quantitative analysis of $E G F R$ status, including EGFRvIII, both at the DNA and mRNA levels in GBM-derived cell cultures, since the available published data did not specify this issue. The reports of Lee et al. [9] and De Witt Hamer et al. [11] allowed spheroid cultures and serum-free conditions to be identified as factors favorable for the stability of the original tumor profile, including gene copy number anomalies. In order to conserve the molecular profile of original tumors in vitro, Fael Al-Mayhani et al. established the protocol based on combination of spheroid and monolayer culture techniques. However, such an experimental strategy did not allow for EGFR amplification maintenance, despite the successful preservation of other genomic abnormalities of GBM [13].

Previous reports have shown that EGFR gene overdosage is gradually lost in adherent GBM-derived cultures under routine conditions $[4,11,22]$. Our results confirmed these findings, demonstrating progressive loss of EGFR amplification followed by EGFRwt downregulation in GBM adherent cultures. In contrast to the EGFR amplification, polysomy 7 resulted in the EGFR locus gain and stabilization in long-term GBM culture, even in the presence of serum. Surprisingly, the EGFRwt expression pattern did not conform to the latter scenario and we observed no overexpression of the tested gene at the mRNA level.

The data mentioned above called our attention to an additional aspect of the experiments aimed at EGFR gene dosage status. In several reports, evaluation of EGFR gene amplification was based exclusively on quantitative techniques (differential PCR or real-time PCR) that enable detection of gene gain only. However, our results emphasized the importance of the distinction between EGFR amplification and polysomy 7 as two different mechanisms of EGFR overdosage. Such an inherent molecular heterogeneity of GBM may cause difficulties in quantitative analysis due to the fact that the low percentage of cells showing EGFR amplification may yield results indistinguishable from polysomy 7 and EGFR locus. Thus, the unequivocal identification of one of these two phenomena requires analysis at a single cell level (e.g. FISH technique).

We have also shown that $E G F R$ amplification and $E G$ FRwt overexpression are indeed sustained in spheroids. However, this fact is only partially consistent with previous reports suggesting the ability of spheroids to preserve primary profile of tumor [9-11]. The precise quantitative analysis revealed that, although the spheroids presented higher EGFR gene dosage than adherent cultures, that dosage was significantly lower in a comparison to parental tumor tissue. This phenomenon has never been noted in previous reports. We speculate that the initial steps of tumor processing and cell culture establishment are responsible for the observed phenomenon, and further research is needed to eliminate this unwelcome effect.

Unfortunately, we found only a single case of GBM showing the presence of EGFRvIII variant. Surprisingly, the evaluation of EGFRvIII status in GBM culture demonstrated that the expression of the truncated form of the receptor was preserved in spheroids at a level comparable to the initial tumor tissue. In contrast, it was completely lost in the adherent culture.

Our findings are potentially significant in the context of research using tumor spheroid cultures as an experimental model for testing novel therapeutics [23, 24]. Also, several recent investigations have been focused on the truncated variant of receptor-EGFRvIII, as a putative therapeutical target [25]. In addition, a report of Martens et al. [26] suggests that responsiveness of the tumor to certain therapeutics is conditioned by the presence of EGFRvIII and dependent on the EGFR amplification status.

It is noteworthy that our experimental approach assumes the use of GBM spheroids derived from parental tumors showing EGFR overdosage or mutational aberration in vivo. Such an approach may offer an alternative way for analyses based on genetically modified glioblastoma cell lines presenting artificial EGFR gene anomalies [27, 28]. Tumor cell lines are unified models devoid of characteristic features specific to individual tumors. This issue seems not to be trivial, especially because of recent reports suggesting the benefits of personalized cancer treatment adjusted to the molecular profile and phenotype of a particular tumor $[8,29,30]$.

Moreover, our results revealing a decreased invasion potential of adherent GBM cells in vitro accompanied by the decline in EGFR expression and capability of spheroids to maintain both of these features seem to be consistent with previous findings suggesting the influence of epidermal growth factor receptor on the invasiveness of tumor cells [19, 31, 32].

In conclusion, our findings confirm that GBM-derived spheroids seem to be a promising tool to preserve original molecular features of the tumor in vitro with a special emphasis on EGFR gene aberrations, including EGFRvIII, regarded as novel therapeutic target. Moreover, it is worth considering whether it is possible to create an alternative experimental model on the basis of long-term GBM culture presenting $E G F R$ gain as a result of polysomy 7. However, in this case, further research is needed in order to achieve $E G F R$ overexpression in vitro.

Finally, the reasons underlying the loss of EGFR anomalies in vitro remain a matter of debate. Identification of the underlying mechanisms may also aid the creation of 
new therapeutic approaches targeted at those cancers showing EGFR aberrations, particularly since GBM cells exhibiting EGFR amplification/overexpression and EGFRvIII presence are regarded as the aggressive and invasive population [7, 33, 34].

Acknowledgments The present study was supported by the Ministry of Science and Higher Education, Poland, grant No. N N401 047337 and Foundation for Polish Science (PARENT-BRIDGE Programme-support for women, No. POMOST_C/15). We would like to thank Dr Maria Constantinou for help in analysis of FISH data and Dr Ewa Golanska for language assistance.

Open Access This article is distributed under the terms of the Creative Commons Attribution Noncommercial License which permits any noncommercial use, distribution, and reproduction in any medium, provided the original author(s) and source are credited.

\section{References}

1. Layfield LJ, Willmore C, Tripp S, Jones C, Jensen RL (2006) Epidermal growth factor receptor gene amplification and protein expression in glioblastoma multiforme: prognostic significance and relationship to other prognostic factors. Appl Immunohistochem Mol Morphol 14(1):91-96

2. Ohgaki H, Kleihues $P$ (2007) Genetic pathways to primary and secondary glioblastoma. Am J Pathol 170(5):1445-1453

3. Leuraud P, Taillandier L, Aguirre-Cruz L, Medioni J, Crinière E, Marie Y, Dutrillaux AM, Kujas M, Duprez A, Delattre JY, Poupon MF, Sanson M (2003) Correlation between genetic alterations and growth of human malignant glioma xenografted in nude mice. Br J Cancer 89(12):2327-2332

4. Pandita A, Aldape KD, Zadeh G, Guha A, James CD (2004) Contrasting in vivo and in vitro fates of glioblastoma cell subpopulations with amplified EGFR. Genes Chromosomes Cancer 39:29-36

5. Giannini C, Sarkaria JN, Saito A, Uhm JH, Galanis E, Carlson BL, Schroeder MA, James CD (2005) Patient tumor EGFR and PDGFRA gene amplifications retained in an invasive intracranial xenograft model of glioblastoma multiforme. Neurooncology 7(2): 164-176

6. Gan HK, Kaye AH, Luwor RB (2009) The EGFRvIII variant in glioblastoma multiforme. J Clin Neurosci 16(6):748-754

7. Nagane M, Lin H, Cavenee WK, Huang HJ (2001) Aberrant receptor signaling in human malignant gliomas: mechanisms and therapeutic implications. Cancer Lett 162(Suppl):S17-S21

8. Mischel PS, Nelson SF, Cloughesy TF (2003) Molecular analysis of glioblastoma: pathway profiling and its implications for patient therapy. Cancer Biol Ther 2:242-247

9. Lee J, Kotliarova S, Kotliarov Y, Li A, Su Q, Donin NM, Pastorino S, Purow BW, Christopher N, Zhang W, Park JK, Fine HA (2006) Tumor stem cells derived from glioblastomas cultured in bFGF and EGF more closely mirror the phenotype and genotype of primary tumors than do serum-cultured cell lines. Cancer Cell 9:391-403

10. Inagaki A, Soeda A, Oka N, Kitajima H, Nakagawa J, Motohashi T, Kunisada T, Iwama T (2007) Long-term maintenance of brain tumor stem cell properties under at non-adherent and adherent culture conditions. Biochem Biophys Res Commun 361(3):586592

11. De Witt Hamer PC, Van Tilborg AA, Eijk PP, Sminia P, Troost D, Van Noorden CJ, Ylstra B, Leenstra S (2008) The genomic profile of human malignant glioma is altered early in primary cell culture and preserved in spheroids. Oncogene 27:2091-2096

12. Rappa G, Mercapide J, Anzanello F, Prasmickaite L, Xi Y, Ju J, Fodstad O, Lorico A (2008) Growth of cancer cell lines under stem cell-like conditions has the potential to unveil therapeutic targets. Exp Cell Res 314:2110-2122

13. Fael Al-Mayhani TM, Ball SL, Zhao JW, Fawcett J, Ichimura K, Collins PV, Watts C (2009) An efficient method for derivation and propagation of glioblastoma cell lines that conserves the molecular profile of their original tumours. J Neurosci Methods 176(2):192-199

14. Rieske P, Golanska E, Zakrzewska M, Piaskowski S, HulasBigoszewska K, Wolańczyk M, Szybka M, Witusik-Perkowska M, Jaskolski DJ, Zakrzewski K, Biernat W, Krynska B, Liberski PP (2009) Arrested neural and advanced mesenchymal differentiation of glioblastoma cells-comparative study with neural progenitors. BMC Cancer 14(9):54

15. Pfaffl MW, Horgan GW, Dempfle L (2002) Relative expression software tool (REST) for group-wise comparison and statistical analysis of relative expression results in real-time PCR. Nucleic Acids Res 30(9):e36

16. Yoshimoto K, Dang J, Zhu S, Nathanson D, Huang T, Dumont R, Seligson DB, Yong WH, Xiong Z, Rao N, Winther H, Chakravarti A, Bigner DD, Mellinghoff IK, Horvath S, Cavenee WK, Cloughesy TF, Mischel PS (2008) Development of a real-time RT-PCR assay for detecting EGFRvIII in glioblastoma samples. Clin Cancer Res 14(2):488-493

17. Theys J, Jutten B, Dubois L, Rouschop KM, Chiu RK, Li Y, Paesmans K, Lambin P, Lammering G, Wouters BG (2009) The deletion mutant EGFRvIII significantly contributes to stress resistance typical for the tumour microenvironment. Radiother Oncol 92(3):399-404

18. Bell HS, Whittle IR, Walker M, Leaver HA, Wharton SB (2001) The development of necrosis and apoptosis in glioma: experimental findings using spheroid culture systems. Neuropathol Appl Neurobiol 27(4):291-304

19. Stein AM, Demuth T, Mobley D, Berens M, Sander LM (2007) A mathematical model of glioblastoma tumor spheroid invasion in a three-dimensional in vitro experiment. Biophys J 92(1):356-365

20. Günther HS, Schmidt NO, Phillips HS, Kemming D, Kharbanda S, Soriano R, Modrusan Z, Meissner H, Westphal M, Lamszus K (2008) Glioblastoma-derived stem cell-enriched cultures form distinct subgroups according to molecular and phenotypic criteria. Oncogene 27:2897-2909

21. Gangemi RM, Griffero F, Marubbi D, Perera M, Capra MC, Malatesta P, Ravetti GL, Zona GL, Daga A, Corte G (2009) SOX2 silencing in glioblastoma tumor-initiating cells causes stop of proliferation and loss of tumorigenicity. Stem Cells 27(1):40-48

22. Bigner SH, Humphrey PA, Wong AJ, Vogelstein B, Mark J, Friedman HS, Bigner DD (1990) Characterization of the epidermal growth factor receptor in human glioma cell lines and xenografts. Cancer Res 50(24):8017-8022

23. Kunz-Schughart LA, Freyer JP, Hofstaedter F, Ebner R (2004) The use of 3-D cultures for high-throughput screening: the multicellular spheroid model. J Biomol Screen 9(4):273-285

24. Khaitan D, Chandna S, Arya MB, Dwarakanath BS (2006) Establishment and characterization of multicellular spheroids from a human glioma cell line; implications for tumor therapy. J Transl Med 4:12

25. Sampson JH, Archer GE, Mitchell DA, Heimberger AB, Bigner DD (2008) Tumor-specific immunotherapy targeting the EGFRvIII mutation in patients with malignant glioma. Semin Immunol 20(5):267-275

26. Martens T, Laabs Y, Günther HS, Kemming D, Zhu Z, Witte L, Hagel C, Westphal M, Lamszus K (2008) Inhibition of 
glioblastoma growth in a highly invasive nude mouse model can be achieved by targeting epidermal growth factor receptor but not vascular endothelial growth factor receptor-2. Clin Cancer Res 14(17):5447-5458

27. Huang PH, Mukasa A, Bonavia R, Flynn RA, Brewer ZE, Cavenee WK, Furnari FB, White FM (2007) Quantitative analysis of EGFRvIII cellular signaling networks reveals a combinatorial therapeutic strategy for glioblastoma. Proc Natl Acad Sci USA 104(31):12867-12872

28. Kwanghee K, Brush JM, Watson PA, Cacalano NA, Iwamoto KS, McBride WH (2008) Epidermal growth factor receptor vIII expression in U87 glioblastoma cells alters their proteasome composition, function, and response to irradiation. Mol Cancer Res 6(3):426-434

29. Lassman AB, Holland EC (2007) Incorporating molecular tools into clinical trials and treatment for gliomas? Curr Opin Neurol 20(6):708-711

30. Mladkova N, Chakravarti A (2009) Molecular profiling in glioblastoma: prelude to personalized treatment. Curr Oncol Rep 11(1):53-61

31. Kang CS, Pu PY, Li YH, Zhang ZY, Qiu MZ, Huang Q, Wang GX (2005) An in vitro study on the suppressive effect of glioma cell growth induced by plasmid-based small interference RNA (siRNA) targeting human epidermal growth factor receptor. J Neurooncol 74(3):267-273

32. Han L, Zhang AL, Xu P, Yue X, Yang Y, Wang GX, Jia ZF, Pu PY, Kang CS (2009) Combination gene therapy with PTEN and EGFR siRNA suppresses U251 malignant glioma cell growth in vitro and in vivo. Med Oncol doi:10.1007/s12032-009-9295-8

33. Nagane M, Coufal F, Lin H, Bögler O, Cavenee WK, Huang HJ (1996) A common mutant epidermal growth factor receptor confers enhanced tumorigenicity on human glioblastoma cells by increasing proliferation and reducing apoptosis. Cancer Res 56:5079-5086

34. Murat A, Migliavacca E, Gorlia T, Lambiv WL, Shay T, Hamou MF, de Tribolet N, Regli L, Wick W, Kouwenhoven MC, Hainfellner JA, Heppner FL, Dietrich PY, Zimmer Y, Cairncross JG, Janzer RC, Domany E, Delorenzi M, Stupp R, Hegi ME (2008) Stem cell-related "self-renewal" signature and high epidermal growth factor receptor expression associated with resistance to concomitant chemoradiotherapy in glioblastoma. J Clin Oncol 26(18):3015-3024 